\title{
OPTIMALISASI PENENTUAN SUMBER PASOKAN KOPI ARABIKA GAYO MELALUI PENDEKATAN HIRARCHICAL CLUSTERING DATA MINING
}

\author{
Arie Saputra ${ }^{1}$ \\ ${ }^{1)}$ Program Studi Teknik Industri, Fakultas Teknik, Universitas Teuku Umar \\ E-mail: ariesaputraubh@gmail.com
}

\begin{abstract}
Gayo coffee scattered in the mountains and being in two districts of the central highlands and Central Aceh district has become the center of world attention. Gayo Arabica coffee has a unique manifold and the added value created by the mountainous nature Gayo. This factor makes Gayo Arabica coffee has the added value that is not replaceable by other similar commodities. The success of the stakeholders Gayo coffee obtain certification which is organic, fairtrade, coffee practice and Geographic indication that can be a proof of the worldwide recognition of the quality and added value of this coffee. The average price of the last on the coffee harvest season in March 2012 ranged between Rp 100.000,until Rp 110.000,- in each Kg grean bean on exporter level. Determination of clusters of farmers the right so that the quality and price of supplies could be predicted well by the cooperative as exporters are very important. These routes and ketelusuran origin coffee blend in one location with other location mebuat coffee quality decreases. Mapping the supply of unclear origin uniformity of the quality of the coffee making is difficult to determine. This effect on selling prices decreased overall coffee farmers to the detriment of farmers with good quality coffee. The good name of the cooperative from the viewpoint of importers deteriorate as evidenced by a decrease in the purchase price of the importer in the contract.The sampling process quality coffee supply also becomes difficult because unhomogenity supply region. Supply region is crucial to the quality of the coffee due influenced the position and height of the land. Thus, this research is expected to help formulate clusters of farmers so that the quality and price of coffee could be improved both in terms of farmers and exporters. The last hope of course the welfare of farmers and other stakeholders could be better.
\end{abstract}

Keywords: Data Mining, Optimization, Gayo Arabica Coffee, Supply Chain

\section{PENDAHULUAN}

Kopi Arabika Gayo, merupakan salah satu jenis komoditi dengan dengan standar kualitas dan harga terbaik di dunia. Kelebihan kopi Gayo terletak pada keunikan cita rasa dan flavor yang dibentuk oleh alam pegunungan gayo sehingga menjadikan nilai tambah komoditi ini tidak tergantikan di dunia. Dari segi harga, menurut Aceh coffee forum (2012) harga kopi Gayo rata-rata dijual pada posisi Rp 100.000,- /Kg dalam bentuk green bean. Harga kopi Gayo jauh lebih tinggi, jika dibandingkan dengan kopi arabika impor dari Vietnam dengan kisaran harga pada rentang Rp 15.000,- sampai Rp 20.000,-. Salah 
satu kelemahan dari perdagangan kopi Gayo adalah masih rendahnya tingkat kesejahteraan petani.

Kopi Gayo merupakan komoditi terbesar kedua setelah kelapa sawit pada sektor pertanian dalam hal sumbangan pendapatan bagi Provinsi Aceh. Akan tetapi dengan nilai tambah komoditi yang tidak tergantikan menjadikan peluang besar bagi sektor ini dikembangkan untuk peningkatan perekonomian masyarakat.

Indikator kesejahteraan petani dapat ditingkatkan dengan penentuan jalur tranportasi yang optimal sehingga biaya produksi bisa ditekan seminimal mungkin. Jalur transportasi dapat ditentukan melalui pengelompokkan (kluster) petani. Pendekatan teknik kluster hirarki dapat menjadi acuan dasar dalam pengelompokan petani berdasarkan posisi lahan. Tujuan khusus dari riset ini adalah :

1. Mendapatkan data variabel posisi lahan dihitung dari titik koperasi petani sehingga pengelompokan (kluster) petani dapat terukur dengan jelas.

2. Membuat kluster petani berdasarkan posisi lahan melalui analisis hirarki kluster data mining.

3. Menentukan nilai harga jual petani berdasarkan pengelompokan sentra produksi kopi

\section{KAJIAN LITERATUR}

Penentuan jalur transportasi kopi Gayo menjadi salah satu parameter yang penting bagi petani maupun koperasi yang bertindak sebagai importir. Parameterparameter atau atribut-atribut kluster menjadi indikator capaian yang menjadi penentu peningkatan kualitas dan produktifitas petani.

Teknik kluster data mining terbukti lebih bisa menghasilkan output yang terukur dengan syarat penentuan atributnya tepat [1]. Teknik hirarki kluster data mining terbagi dua yaitu agglomerative (penempelan) dan divisive (pemisahan) [2]. Hampir 85\% kawasan Aceh Tengah dan Bener Meriah ditanami ditanami kopi Arabika Gayo [3].

Kualitas dan kuantitas kopi Gayo semakin lama semakin menurun. Salah satu penyebabnya karena belum terpetakan dengan jelas kelompok (kluster) lahan dengan kualitas yang baik (terase rendah) oleh koperasi. Di sisi lain, dengan pengelompokkan lahan dengan kualitas biji kopi yang baik bisa memudahkan koperasi dalam menentukan posisi harga beli yang tepat bagi petani berdasarkan bobot (beban) rute tempuh petani ke koperasi. Oleh karena itu, atribut kluster harus mewakili kualitas, beban rute transportasi, produktifitas lahan, ketelusuran serta beban rute transportasi dari biji kopi yang dihasilkan petani.

Karena itu informasi yang lengkap dan utuh berdasarkan parameter yang tepat dalam menentukan harga beli koperasi untuk peningkatan kesejahteraan petani. Melalui pemetaan jalur transportasi lahan akan sangat membantu bagi dua pelaku yaitu petani sebagai pemasok dan koperasi sebagai importir.

\section{METODOLOGI PENELITIAN}

\subsection{Lokasi Pengambilan Sampel}

Sampel lahan akan diambil sebanyak 97 lahan (petani) yang mewakili 25 desa dan 7 kecamatan. Kawasan Aceh Tengah terdiri dari 14 kecamatan dimana 7 kecamatan terpilih merupak sentra produksi dari kopi Gayo. Kecamatan dan desa pemilihan sampel terdiri dari:

1) Kecamatan Pegasing dengan jumlah 6 desa. 
2) Kecamatan Kebayakan dengan jumlah 3 desa.

3) Kecamatan Atu lintang dengan jumlah 4 desa.

4) Kecamatan Jagong dengan jumlah 4 desa.

5) Kecamatan Silih Nara dengan jumlah 4 desa.

6) Kecamatan bintang dengan jumlah 4 desa.

\subsection{Atribut Kluster}

Pemilihan atribut kluster petani seperti yang dijelaskan diatas harus bisa mewakili kualitas produk. Salah satu faktor terpenting yang menentukan kualitas biji kopi adalah ketinggian lahan. Selain dari itu pertimbangan harga jual kopi petani juga dilihat dari jarak tempuh. Kesulitan rute yang ditempuh oleh petani juga menjadi faktor pertimbangan. Pada umumnya lahan dengan ketinggian yang dianggap sangat baik berada pada lokasi yang susah ditempuh (areal perbukitan) serta jarak yang sangat jauh dari koperasi.

Atribut yang bisa dijadikan pertimbang disini adalah kecepatan rata-rata dan waktu tempuh petani menuju koperasi. Produktifitas lahan juga menjadi pertimbangan bagi koperasi dalam menilai harga jual kopi petani. Hal ini disebabkan karena koperasi terikat kontrak dengan importir dalam memenuhi kuota pasokan. Semakin luas lahan yang dimiliki oleh seorang petani maka secara umum kemungkinan jumlah produksinya semakin besar. Jika disimpulkan ada 6 atribut kluster yang akan di definisikan dalam penelitian ini yaitu luas lahan, jarak, kecepatan rata-rata, titik koordinat, ketinggian dan waktu tempuh. Penentuan titik koordinat berguna dalam melihat lokasi pengelompokkan lahan petani yang akan di buat klusternya.

Pemilihan teknik hirarki klustering berdasarkan kemampuan metode yang lebih baik dibandingkan k-means clustering dalam menjustifikasi jumlah kluster. Kluster Hirarki dianggap lebih baik dibandingkan dengan k-meas karena justifikasi jumlah kluster bisa ditentukan berdasarkan hasil akhir dari analisis data. Sehingga, pengguna bisa menentukan dengan tepat berdasarkan justifikasi kebutuhan penelitian dan objek penelitian. Sementara, $k$-means clustering mempunyai sedikit efek bias karena jumlah kluster ditentukan di awal penelitian.

\section{HASIL DAN DIKSKUSI}

Analisis data akan diolah melalui software Matlab 2010b untuk mendapatkan jumlah kluster dari masing petani yang terdiri atas 7 kecamatan. Data yang akan diperoleh berupa jumlah definif kluster dari setiap petani yang telah dipetakan sebelumnya. Data ini akan memberikan gambaran bagi koperasi dalam menentukan prioritas lokasi asal kopi serta kemungkinan penempatan kolektor (pengumpul) kopi pada masing masing lokasi kluster. Kluster juga akan mewakili kompleksitas penilaian harga jual kopi mulai dari kualitas sampai jumlah produksi petani

Tabel 1 Rekapitulasi data parameter klustering

\begin{tabular}{ccccccccc}
\hline No & $\begin{array}{c}\text { Luas } \\
\text { lahan }\end{array}$ & jarak & $\begin{array}{c}\text { Kec. } \\
\text { Rata- } \\
\text { rata }\end{array}$ & $\begin{array}{c}\text { Titik } \\
\text { koordinat } \\
\text { lintang }\end{array}$ & $\begin{array}{c}\text { titik } \\
\text { koordinat } \\
\text { bujur }\end{array}$ & Ketinggian & $\begin{array}{c}\text { kondisi } \\
\text { jalan }\end{array}$ & $\begin{array}{c}\text { Waktu } \\
\text { Tempuh }\end{array}$ \\
\hline 1 & 0.8 & 1000 & 50 & 4.5762 & 96.8139 & 1211.5 & 4 & 260 \\
2 & 2 & 1350 & 50.2 & 4.5754 & 96.8138 & 1207 & 4 & 365 \\
3 & 1 & 1400 & 50.1 & 4.5765 & 96.8131 & 1197.5 & 4 & 415 \\
4 & 0.25 & 590 & 16.6 & 4.5816 & 96.8905 & 1202 & 1 & 190
\end{tabular}




\begin{tabular}{|c|c|c|c|c|c|c|c|c|}
\hline 5 & 0.5 & 970 & 15.1 & 4.5813 & 96.8063 & 1210.5 & 1 & 303 \\
\hline 6 & 1 & 1200 & 14.9 & 4.5812 & 96.8059 & 1236 & 1 & 360 \\
\hline 7 & 0.5 & 1250 & 14.2 & 4.5803 & 96.8054 & 1245.5 & 1 & 360 \\
\hline 8 & 2 & 4100 & 37.6 & 4.5637 & 96.8359 & 1272 & 4 & 540 \\
\hline 9 & 1.5 & 8200 & 29.4 & 4.5648 & 96.8549 & 1391.5 & 4 & 951 \\
\hline 10 & 1.5 & 6000 & 37.6 & 4.5468 & 96.8549 & 1391.5 & 4 & 903 \\
\hline 11 & 1 & 7880 & 26.65 & 4.5592 & 96.8546 & 1413 & 4 & 1120 \\
\hline 12 & 2 & 18900 & 39.3 & 4.4774 & 96.7796 & 1245.5 & 4 & 1800 \\
\hline 13 & 1 & 19500 & 35.4 & 4.4732 & 96.7689 & 1646.5 & 4 & 1872 \\
\hline 14 & 2 & 19530 & 34.2 & 4.4687 & 96.7645 & 1562.5 & 4 & 1998 \\
\hline 15 & 1 & 20153 & 35 & 4.4732 & 96.7734 & 1634 & 4 & 2106 \\
\hline 16 & 1 & 31510 & 30.5 & 4.5067 & 96.7652 & 1551.5 & 4 & 3996 \\
\hline 17 & 1 & 31781 & 29.9 & 4.5102 & 96.7616 & 1540.5 & 4 & 4313.4 \\
\hline No & $\begin{array}{l}\text { Luas } \\
\text { lahan }\end{array}$ & jarak & $\begin{array}{c}\text { Kec. } \\
\text { Rata- } \\
\text { rata }\end{array}$ & $\begin{array}{c}\text { Titik } \\
\text { koordinat } \\
\text { lintang }\end{array}$ & $\begin{array}{c}\text { titik } \\
\text { koordinat } \\
\text { bujur }\end{array}$ & Ketinggian & $\begin{array}{c}\text { kondisi } \\
\text { jalan }\end{array}$ & $\begin{array}{c}\text { Waktu } \\
\text { Tempuh }\end{array}$ \\
\hline 18 & 1 & 32880 & 28.7 & 4.5089 & 96.756 & 1551 & 4 & 4571.4 \\
\hline 19 & 1.5 & 33020 & 28.1 & 4.5103 & 96.7547 & 1542 & 4 & 4633.8 \\
\hline 20 & 0.5 & 6600 & 39 & 4.5459 & 96.7933 & 1288 & 4 & 540 \\
\hline 21 & 0.5 & 7180 & 37.2 & 4.5454 & 96.7892 & 1283 & 4 & 720 \\
\hline 22 & 2 & 7440 & 35.7 & 4.5462 & 96.7877 & 1370.5 & 4 & 944 \\
\hline 23 & 0.5 & 8200 & 50 & 4.6424 & 96.8652 & 1237.5 & 5 & 1004 \\
\hline 24 & 0.5 & 8860 & 48.1 & 4.6411 & 96.8722 & 1237 & 4 & 1094 \\
\hline 25 & 0.5 & 8920 & 43.8 & 4.6472 & 96.864 & 1275 & 4 & 1123 \\
\hline 26 & 0.5 & 9640 & 40.1 & 4.65 & 96.8637 & 1297 & 4 & 1208 \\
\hline 27 & 1 & 10700 & 39.4 & 4.6524 & 96.8289 & 1322.5 & 5 & 979 \\
\hline 28 & 1 & 11250 & 39.1 & 4.6564 & 96.8287 & 1360.5 & 5 & 1065 \\
\hline 29 & 1 & 11670 & 39.7 & 4.6591 & 96.8295 & 1317 & 4 & 1162 \\
\hline 30 & 0.5 & 12080 & 40.1 & 4.6597 & 96.8269 & 1313 & 4 & 1226 \\
\hline 31 & 1.5 & 12500 & 34.3 & 4.6596 & 96.8516 & 1284.5 & 4 & 1265 \\
\hline 32 & 1 & 12910 & 33.4 & 4.658 & 96.8543 & 1309.5 & 4 & 1371 \\
\hline 33 & 1 & 13140 & 33.8 & 4.6602 & 96.8548 & 1309 & 4 & 1415 \\
\hline 34 & 1 & 14140 & 31.7 & 4.6602 & 96.8627 & 1376 & 4 & 1676 \\
\hline 35 & 1 & 18900 & 40.6 & 4.4678 & 96.7912 & 1723.5 & 5 & 2281 \\
\hline 36 & 2 & 19310 & 40.1 & 4.4666 & 96.7941 & 1743.5 & 5 & 1745 \\
\hline 37 & 2 & 20000 & 39.2 & 4.4643 & 96.7997 & 1803.5 & 5 & 1878 \\
\hline 38 & 2 & 25400 & 37.4 & 4.4646 & 96.8092 & 1873 & 5 & 2098 \\
\hline 39 & 1 & 26900 & 25.3 & 4.4604 & 96.8163 & 1842.5 & 5 & 2319 \\
\hline 40 & 1 & 27200 & 24.9 & 4.4605 & 96.8195 & 1821.5 & 5 & 2374 \\
\hline 41 & 1 & 28300 & 23.5 & 4.4649 & 96.8149 & 1757 & 4 & 2694 \\
\hline 42 & 1 & 28510 & 22.9 & 4.4661 & 96.8154 & 1737 & 4 & 2802 \\
\hline 43 & 2 & 21700 & 35.7 & 4.4547 & 96.7966 & 1517 & 5 & 1959 \\
\hline 44 & 1 & 22230 & 33.1 & 4.4554 & 96.8014 & 1538 & 4 & 2061 \\
\hline
\end{tabular}




\begin{tabular}{|c|c|c|c|c|c|c|c|c|}
\hline 45 & 1 & 22770 & 32.5 & 4.4514 & 96.8 & 1520 & 4 & 2216 \\
\hline 46 & 0.5 & 22890 & 30.1 & 4.4514 & 96.7989 & 1512.5 & 4 & 2268 \\
\hline 47 & 2 & 34890 & 37.4 & 4.4182 & 96.7734 & 1422.5 & 5 & 4044 \\
\hline 48 & 1 & 35640 & 37.5 & 4.4154 & 96.7705 & 1418 & 4 & 4170 \\
\hline 49 & 1.5 & 36450 & 37.8 & 4.413 & 96.7689 & 1416 & 4 & 4250 \\
\hline 50 & 1 & 36880 & 36.1 & 4.4096 & 96.7674 & 1401 & 4 & 4330 \\
\hline 51 & 1 & 43380 & 37.4 & 4.3976 & 96.7467 & 1586 & 5 & 4960 \\
\hline 52 & 1 & 44410 & 35.3 & 4.3989 & 96.7385 & 1494.5 & 4 & 5204 \\
\hline 53 & 1 & 44510 & 35.4 & 4.399 & 96.7376 & 1489.5 & 4 & 5231 \\
\hline 54 & 1 & 44790 & 32.2 & 4.4006 & 96.7375 & 1485.5 & 4 & 5345 \\
\hline 55 & 1 & 45890 & 37.4 & 4.3822 & 96.7477 & 1540.5 & 5 & 5534 \\
\hline 56 & 1 & 46500 & 36.1 & 4.3806 & 96.7401 & 1526 & 5 & 5694 \\
\hline 57 & 0.5 & 46930 & 35.9 & 4.3829 & 96.7382 & 1522 & 5 & 5810 \\
\hline No & $\begin{array}{l}\text { Luas } \\
\text { lahan }\end{array}$ & jarak & $\begin{array}{c}\text { Kec. } \\
\text { Rata- } \\
\text { rata }\end{array}$ & $\begin{array}{c}\text { Titik } \\
\text { koordinat } \\
\text { lintang }\end{array}$ & $\begin{array}{c}\text { titik } \\
\text { koordinat } \\
\text { bujur }\end{array}$ & Ketinggian & $\begin{array}{c}\text { kondisi } \\
\text { jalan }\end{array}$ & $\begin{array}{c}\text { Waktu } \\
\text { Tempuh }\end{array}$ \\
\hline 58 & 0.8 & 47730 & 34.4 & 4.3781 & 96.7409 & 1523.5 & 5 & 5914 \\
\hline 59 & 1 & 52030 & 26.6 & 4.3748 & 96.7755 & 1519 & 5 & 6503 \\
\hline 60 & 1 & 54430 & 25.3 & 4.3662 & 96.7784 & 1611 & 5 & 6846 \\
\hline 61 & 1 & 53600 & 25.9 & 4.374 & 96.7747 & 1530 & 5 & 7002 \\
\hline 62 & 0.5 & 53840 & 25.8 & 4.3743 & 96.7746 & 1540.5 & 5 & 7065 \\
\hline 63 & 1 & 55740 & 28.2 & 4.3873 & 96.752 & 1442.5 & 5 & 7058 \\
\hline 64 & 1 & 56290 & 28 & 4.3904 & 96.7944 & 1436 & 5 & 7192 \\
\hline 65 & 1 & 57590 & 27.3 & 4.387 & 96.7904 & 1453.5 & 5 & 7516 \\
\hline 66 & 1 & 58550 & 29.1 & 4.3814 & 96.7899 & 1458.5 & 5 & 7687 \\
\hline 67 & 2 & 6460 & 35.8 & 4.5938 & 96.7741 & 1162 & 4 & 634 \\
\hline 68 & 1 & 7350 & 34.1 & 4.5888 & 96.7709 & 1187.5 & 4 & 813 \\
\hline 69 & 1 & 7350 & 33.2 & 4.5844 & 96.7728 & 1276 & 3 & 1031 \\
\hline 70 & 1 & 7950 & 30.7 & 4.5853 & 96.7744 & 1288.5 & 3 & 1199 \\
\hline 71 & 1 & 12260 & 29.3 & 4.6559 & 96.7417 & 1083.5 & 4 & 1328 \\
\hline 72 & 1 & 13100 & 28.1 & 4.6607 & 96.7436 & 1083 & 4 & 1454 \\
\hline 73 & 1 & 13530 & 27.3 & 4.6628 & 96.7642 & 1119.5 & 4 & 1527 \\
\hline 74 & 1 & 14060 & 27.5 & 4.667 & 96.7481 & 1109.5 & 4 & 1624 \\
\hline 75 & 1 & 21700 & 31 & 4.6247 & 96.69 & 861 & 4 & 2044 \\
\hline 76 & 1 & 22310 & 30.8 & 4.6266 & 96.6855 & 886.5 & 4 & 2132 \\
\hline 77 & 1 & 23310 & 21.6 & 4.6527 & 96.6779 & 858 & 4 & 2304 \\
\hline 78 & 1 & 24030 & 21.9 & 4.6521 & 96.6723 & 847 & 4 & 2427 \\
\hline 79 & 0.5 & 24300 & 25.4 & 4.65 & 96.6771 & 993.5 & 4 & 2520 \\
\hline 80 & 1 & 25400 & 23.9 & 4.6521 & 96.6772 & 1003.5 & 4 & 2709 \\
\hline 81 & 1 & 26240 & 24.5 & 4.6469 & 96.6725 & 1026 & 4 & 3223 \\
\hline 82 & 1 & 26124 & 23.6 & 4.6485 & 96.6723 & 1036 & 4 & 3448 \\
\hline 83 & 1 & 21900 & 40.3 & 4.6321 & 96.9456 & 1287.5 & 4 & 1967 \\
\hline 84 & 1 & 22150 & 40.1 & 4.6339 & 96.9469 & 1321.5 & 4 & 2029 \\
\hline
\end{tabular}




\begin{tabular}{ccccccccc}
85 & 1 & 22920 & 39.7 & 4.6353 & 96.9515 & 1425.5 & 4 & 2196 \\
86 & 1 & 23410 & 37.8 & 4.6378 & 96.9492 & 1485.5 & 4 & 2324 \\
87 & 1 & 25800 & 31.6 & 4.6161 & 96.9753 & 1246.5 & 4 & 2408 \\
88 & 0.8 & 26690 & 30.7 & 4.6121 & 96.9824 & 1270.5 & 4 & 2493 \\
89 & 0.5 & 27110 & 31.2 & 4.6109 & 96.9389 & 1265.5 & 4 & 2563 \\
90 & 0.7 & 27580 & 31.4 & 4.6078 & 96.9885 & 1264 & 4 & 2672 \\
91 & 1 & 27790 & 35 & 4.6073 & 96.9887 & 1256 & 4 & 2702 \\
92 & 1 & 28150 & 36.5 & 4.6063 & 96.9899 & 1254.5 & 4 & 2843 \\
93 & 0.5 & 28720 & 38.6 & 4.6037 & 969928 & 1239.5 & 4 & 2943 \\
94 & 1 & 29120 & 37.4 & 4.6017 & 96.9956 & 1244.5 & 4 & 2990 \\
\hline
\end{tabular}

\begin{tabular}{ccccccccc}
\hline No & $\begin{array}{c}\text { Luas } \\
\text { lahan }\end{array}$ & jarak & $\begin{array}{c}\text { Kec. } \\
\text { Rata- } \\
\text { rata }\end{array}$ & $\begin{array}{c}\text { Titik } \\
\text { koordinat } \\
\text { lintang }\end{array}$ & $\begin{array}{c}\text { titik } \\
\text { koordinat } \\
\text { bujur }\end{array}$ & Ketinggian & $\begin{array}{c}\text { kondisi } \\
\text { jalan }\end{array}$ & $\begin{array}{c}\text { Waktu } \\
\text { Tempuh }\end{array}$ \\
\hline 95 & 0.5 & 31620 & 34.4 & 4.5889 & 96.0119 & 1279 & 4 & 3249 \\
96 & 1 & 32840 & 34.2 & 4.5845 & 96.0202 & 1305 & 4 & 3422 \\
97 & 0.5 & 33720 & 34.7 & 4.5854 & 96.0137 & 1268 & 4 & 3552 \\
98 & 1 & 34130 & 34.3 & 4.5864 & 96.0112 & 1272 & 4 & 3728 \\
\hline
\end{tabular}

Sumber : Pengolahan data, 2013

Hasil olah data klustering sementara dengan menggunakan software matlab 2010b

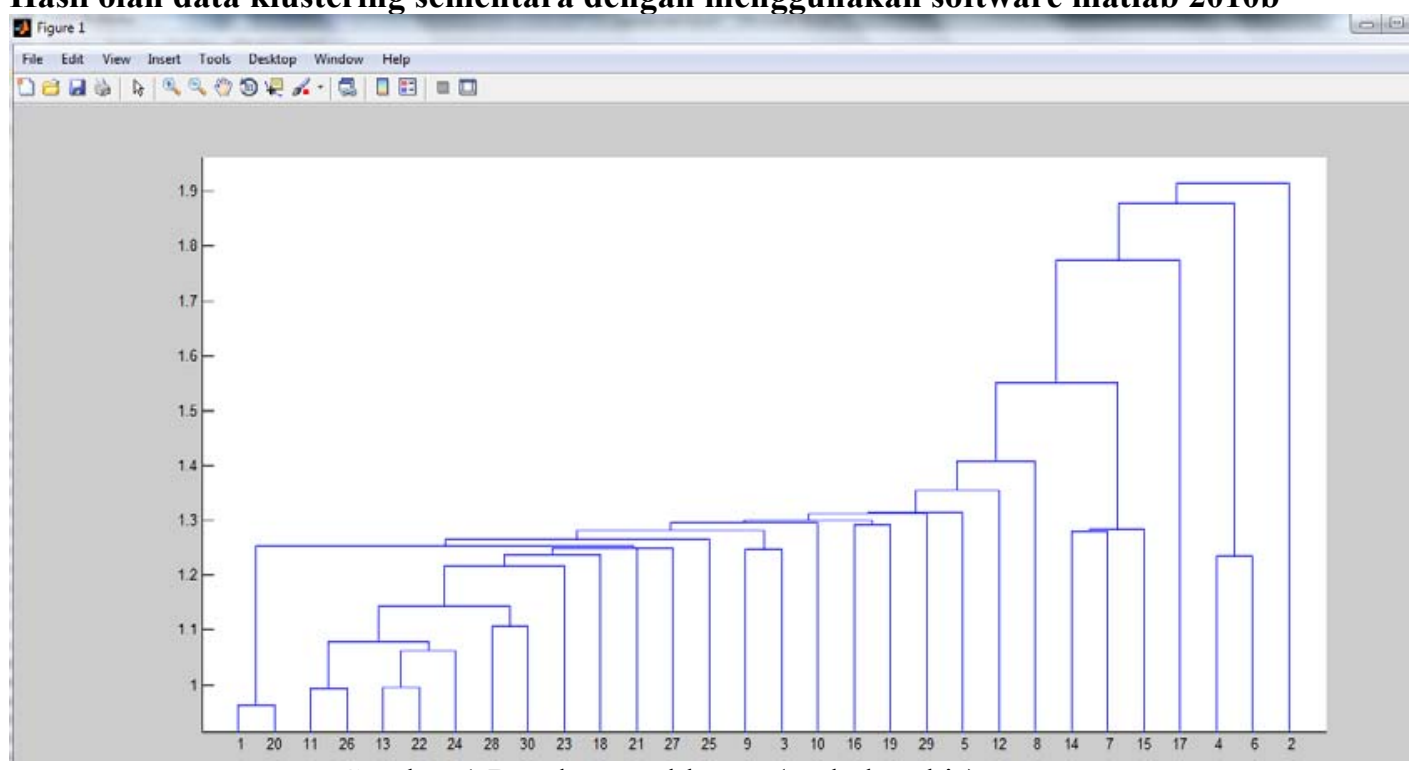

Gambar 1 Dendogram kluster (mahalanobis)

Sumber : Pengolahan data Matlab edisi 10b, 2013 


\section{KESIMPULAN}

Dendrogram kluster petani kopi Arabika yang diwakili 100 orang petani dari total 12 kecamatan yang ada, maka bisa dilakukan proses pemotongan (cutting) dengan melihat kedekatan jarak vertikal yang dihasilkan. Melalui proses cutting, diperoleh kesimpulan terdapat 7 Kluster sumber pasokan kopi Arabika yang bisa memberikan keuntungan maksimal terhadap petani maupun koperasi. Ke tujuh kluster tersebut adalah Kluster 1: petani 2, kluster 2: petani 4 dan 6 yang mewakili kecamatan jagong, kluster 3: petani 17 yang mewakili kecamatan, kluster 4: petani 7, 14 dan15 yang mewakili kecamatan kebayakan., kluster 5: petani 8 dan kluster 6: petani 12 mewakili kecamatan pegasing. Sementara kluster 7 mewakili sisa petani yang tidak termasuk kedalam kluster sebelumnya. Kluster 7 merupakan perwakilan sumber pasokan dari kecamatan bintang. Dari hasil analysis ini dapat disimpulkan kecamatan bintang merupakan sumber pasokan yang dapat memberikan optimalisasi keuntungan baik dari sisi koperasi maupun petani. Penelitian lebih lanjut diperlukan untuk menentukan peringkat (ranking) kluster dan nilai optimlisasi yang bisa diperikan kepada pelaku dalam hal ini petani dan koperasi. Rangking dan nilai optimalisasi ini akan sangat berguna dalam menentukan proses penanganan yang diperlukan terhadap daerah sumber pasokan yang telah ditentukan sebelumnya.

\section{DAFTAR PUSTAKA}

[1] Berry, MW. 2004. Text Mining: Clustering, Classification and Retrieval. New York: Springer.

[2] Gan, G., Ma, C., Wu, J. 2007. Data Clustering: Theory, Algorithms and Application. Philadelpia: ASA-SIAM Series on Statistics and Applied Probability

[3] Jaya, R., Machfud, Ismail, M. 2011. Application of ISM and ME-MCDM Techniques for the Identification of Stakeholders Position and Activity Alternative to Improve Quality of Gayo Coffee. Bogor: Jurnal teknologi Industri Pertanian Vol $21(1), 1-8$. 